\title{
El control jurisdiccional del urbanismo de Marbella, 1991-2006
}

\author{
Ángel Sánchez Blanco \\ Catedrático de Derecho Administrativo \\ Universidad de Málaga
}

\begin{abstract}
Sumario: I. LAS DESVIACIONES JURÍDICAS DEL AYUNTAMIENTO DE MARBELLA. - II. LICENCIAS URBANÍSTICAS Y PLAN GENERAL DE ORDENACIÓN URBANA EN LA DOCTRINA JURISPRUDENCIAL. 1. No son admisibles actuaciones urbanísticas municipales sin la cobertura de un Plan General de Ordenación Urbanística. 2. El requisito de la publicación para la vigencia de los Planes de Urbanismo. 3. Los Planes vigentes determinan el contenido reglado de la licencia. 4. El desconcertante pero justificado tránsito del no publicado Plan General de Ordenación Urbana de 1986 al precedente Plan General de Ordenación urbana de1968. 5. La implicación penal de las licencias urbanísticas. 6. La integración de los contenidos de la Ley de Ordenación Urbanística de Andalucía de 2002. 7. La integración de medidas cautelares y la alegación del principio de seguridad jurídica y de autonomía local, y su ponderación con los intereses supralocales representados por la Comunidad Autónoma. 8. La implicación del concepto de Derecho Urbanístico, del interés supralocal y de la ordenación del territorio.-III. REFLEXIÓN FINAL.
\end{abstract}

\section{LAS DESVIACIONES JURÍDICAS DEL AYUNTAMIENTO DE MARBELLA}

El análisis de las actuaciones urbanísticas del Ayuntamiento de Marbella, en el periodo 1991-2006, permite apreciar una definida línea de acción que se diseña sobre la base de la reducida eficacia en el control jurídico de las actuaciones municipales. Dos fechas lo delimitan: el 16 de mayo de 1991, con la mayoría absoluta en las elecciones municipales del Grupo Independiente Liberal, y el Real Decreto 421/2006, de 7 de abril, de disolución del Ayuntamiento de Marbella.

La carencia de instrumentos de ordenación del territorio, por inaplicación de las previsiones de la Ley 1/1994, de Ordenación del Territorio de Andalucía, redujo los instrumentos de programación territorial del municipio al Plan General de Ordenación Urbana, aprobado en 1986, pero cuya publicación no se realizó por la Junta de Andalucía hasta finales del año $2000^{1}$, con la consecuencia, a partir de 1990, de no poder ser considerado vigente por efecto de la doctrina jurisprudencial que precisó la necesidad de publicación de los Planes en los diarios oficiales como requisito para su vigencia ${ }^{2}$.

\footnotetext{
1 Resolución de la Delegación Provincial de Málaga de la Consejería de Obras Públicas y Transportes, de 13 de noviembre de 2000, Boletín Oficial de la Provincia de Málaga de 28 de noviembre de 2000.

2 SsTS 10 de abril de 1990, Pte. Mg. Sr. Delgado BARRIO, RJ 1990\1990; 11 de julio de 1991 RJ 1991.6352, Pte. Mg. Sr. Martín Martín, y 22 de octubre de 1991, Pte. Mg. Sr. García Estartús, RJ 1991\8375.
} 
La invalidación de la vigencia del Plan General de Ordenación Urbana de Marbella de 1986 ofreció a quienes operaban desde el mismo Ayuntamiento con la firme voluntad de relativizar cualquier normativa que pudiera constreñir su libre voluntad un inestimable marco desregulado. El Ayuntamiento de Marbella estaba, de modo implícito, habilitado para operar sin condicionantes; con una libertad de diseño en la que confluía la posibilidad de determinaciones incondicionadas, alimentadas por la dogmática de la desregulación y la consideración de la actividad urbanística como inapreciable motor de desarrollo, sin olvidar los argumentos derivados del necesario respeto al autonomismo municipal, potenciado por la carencia de cualquier marco asociativo intermunicipal que pudiera requerir la necesaria integración de cualquier decisión del Ayuntamiento de Marbella en la perspectiva de los Ayuntamientos limítrofes.

Los incondicionados diseños del Ayuntamiento de Marbella se proyectaron en licencias urbanísticas concedidas en función de la libre ocurrencia de los titulares municipales, sin reparar en el posible conflicto con las premisas urbanísticas del dominio público, de las redes de infraestructuras, de las zonas verdes o de consolidados derechos de los propietarios colindantes.

Las licencias expedidas por el Ayuntamiento de Marbella ignoraron los condicionantes del dominio público marítimo terrestre y del dominio público hidrológico y no tuvieron inconveniente en proyectar edificaciones sobre dunas, playas, ríos y arroyos, sin excluir la invasión de espacios arqueológicos.

Por supuesto, las redes de infraestructuras de abastecimiento, energéticas, de telecomunicaciones, incluidas las terrestres de comunicación, no fueron objeto de consideración por unos titulares municipales que operaban con la premisa de que cualquier superficie libre era susceptible de un destino inmobiliario materializador de beneficios privados y necesariamente compartidos entre los propietarios y los titulares del Ayuntamiento al margen de los procedimientos administrativos locales.

En el momento en que la acumulación de las incondicionadas licencias de edificación requirió articularse en un Plan, para orientación de los propios titulares municipales, se operó con el argumento de la convalidación de las otorgadas mediante la recepción en el nuevo Plan General de Ordenación Urbana, con la voluntad de agregar la consecuencia de desactivar los numerosos recursos jurídicos que, por ejercicio de acción pública o por defensa de derechos de afectado, se habían formalizado en contra de las licencias otorgadas. Pero la iniciativa de un nuevo Plan General para el municipio tuvo el benéfico efecto de integrar la necesaria intervención de un nuevo ámbito de competencia administrativa: la Junta de Andalucía, mediante el ejercicio de las competencia en materia de ordenación del territorio y urbanismo atribuidas a la Consejería de Obras Públicas y Transportes y, con ello, el marco de las relaciones interadministrativas ofreció la oportunidad de comenzar a normalizar en Derecho la consolidada vía de hecho del Ayuntamiento de Marbella. 
No obstante, nuevos argumentos de defensa de parte, más que jurídico institucionales, se cruzaron en el espacio temporal abierto a los desatinos, que solo pudieron cerrarse con la disolución de la Corporación Municipal, que operaba con la firma convicción de que todo era posible en Marbella y que la normativa jurídica no era un condicionante.

La aprobación inicial por el Ayuntamiento de un nuevo Plan General Municipal de Urbanismo de Marbella pretendió consolidar la vía de hecho. Operó el argumento de la implícita aprobación, por silencio administrativo, del Plan General, como consecuencia de la estimación, por el propio Ayuntamiento, de no haberse pronunciado la Junta de Andalucía en la resolución del expediente iniciado por el Ayuntamiento, con el efecto de dar el Ayuntamiento por aprobado y vigente el $\mathrm{Plan}^{3}$, criterio que, no sin paradojas, coexiste con los pronunciamientos jurisprudenciales que ante el vacío de plan urbanístico, por la no publicación del Plan de 1986, precisan como vigente el previo Plan General de Ordenación Urbana de 1968.

La osadía de los titulares del municipio de Marbella tiene también la perfilada expresión de la aprobación del Texto Refundido del Plan General de Ordenación Urbana de Marbella, integrador de las previsiones del Plan de 1986 y del plan que estimaron vigente por aprobación en aplicación de lo que consideraron como silencio administrativo de la Junta de Andalucía ${ }^{4}$.

La intervención parlamentaria incorpora una salida al caos de tiempos y modos y la Ley de Ordenación Urbanística de Andalucía de 2002, precisó las competencias de la Comunidad Autónoma de Andalucía en materia de ordenación urbanística, y superó el vacío normativo que no suplía la Ley estatal después de la Sentencia del Tribunal Constitucional 61/1997 y de la Ley del Suelo de 1998.

Dos precisos artículos de la Ley de Ordenación Urbanística ofrecen el punto de apoyo para reconducir la voluntad distorsionadora de los titulares municipales de Marbella, los artículos 189 y 190, redactados bajo el común denominador de «Las licencias u órdenes de ejecución incompatibles con la ordenación urbanística», que habilitan para la revisión y suspensión de las licencias urbanísticas y de las órdenes de ejecución, y que, en concordancia con la tipología de infracciones y sanciones, ofrecen cobertura a la incorporación del concepto de ordenación urbanística, como título competencial anejo a la ordenación territorial en el ámbito de las competencias de la Comunidad Autónoma de Andalucía.

\footnotetext{
3 Criterio invalidado por Auto de la Sala de lo Contencioso Administrativo de Málaga de 7 de agosto de 1998, ratificado por Sentencia del Tribunal Supremo de 10 de marzo de 2001, Pte, Mg. Sr. YAGUE GIL, RJ $2001 \backslash 3769$.

4 Desautorizado por la Sala de lo Contencioso Administrativo de Málaga con fundamento en que «por lo que se refiere al acuerdo relativo a la aprobación del texto refundido de la revisión del Plan General de Ordenación Urbana que el mismo, al venir necesitado de una aprobación posterior por el órgano autonómico correspondiente, no puede considerarse como acto firme y como tal susceptible de impugnación» STSJAnd 13 diciembre 2005, Pte. Mg. Sr. DE LA TORRE DEZA, JUR $2006 \backslash 213560$.
} 
Los preceptos de la Ley de Ordenación Urbanística aportan al control jurisdiccional de las licencias, y al simulacro de planeamiento municipal de los titulares del Ayuntamiento de Marbella, los resortes para reconducir a Derecho las vías de hecho abiertas por una inasimilable práctica municipal en el largo periodo 1991-2006.

El determinismo de la alternativa parlamentaria de 2002, ha tenido el complemento de la jurisprudencia de la Sala de lo Contencioso de Málaga del Tribunal Superior de Justicia de Andalucía, que ha operado, en el control de las desviaciones fácticas instrumentadas desde el Ayuntamiento de Marbella, y en el control de los argumentos que pretendieron avalarlas, en el marco de la consolidada doctrina del Tribunal Supremo relativa a las licencias urbanísticas.

La consolidación de la doctrina jurisprudencial coexiste con los lapsos temporales que los correlativos procesos judiciales han implicado, periodos temporales que se hacen objeto de concreción en las correspondientes Sentencias de la Sala de lo Contencioso Administrativo de Málaga analizadas, con plazos que se van incrementando en el transcurso de los años noventa al dos mil, desde los cinco a los nueve años, con solo una excepción de pendencia judicial de dos años y cuatro meses, sin reparar en el dato de que la previsión de estos desproporcionados lapsos temporales ha sido parte de la metodología de acción de quienes detentaron potestades municipales en el Ayuntamiento de Marbella para el diseño de sus fraudulentas maquinaciones.

\section{LICENCIAS URBANÍSTICAS Y PLAN GENERAL DE ORDENACIÓN URBANA EN LA DOCTRINA JURISPRUDENCIAL}

La secuencia argumental que estructura la jurisprudencia de la Sala de lo Contencioso Administrativo de Málaga en el control de la actividad urbanística desarrollada en el Ayuntamiento de Marbella tiene un componente determinante: no son admisibles actuaciones urbanísticas municipales sin cobertura en los instrumentos de programación urbanística; los Planes urbanísticos tienen que ser publicados para poderlos considerar vigentes; no son admisibles actuaciones urbanísticas municipales sin Plan en la que se inserten y que las avale y los Planes vigentes determinan el contenido reglado de las licencias, determinaciones básicas que se proyectan en la conceptualización del derecho urbanístico, los intereses supramunicipales y la ordenación territorial.

\section{No son admisibles actuaciones urbanísticas municipales sin la cobertura de un Plan General de Ordenación Urbanística}

Desde los contundentes pronunciamientos del Tribunal Supremo que consolidaron el carácter normativo de los Planes hasta sus más recientes pronuncia- 
mientos, la exigencia de Plan para legitimar la actuación urbanística pública con la ponderada integración de las expectativas de los propietarios, es constatable una equilibrada secuencia argumental que contrasta con la desequilibrada instrumentación urbanística realizada en el Ayuntamiento de Marbella.

La Sentencia 10 de junio de 1977 contiene el siguiente fundamento, que reproduce el tenor de la precedente sentencia de 15 de noviembre de $1974^{5}$ :

«Después de la vigencia de la Ley tantas veces citada de 12 de mayo de 1956, la facultad de edificar en suelo propio, como una de las integrantes del dominio, no es ya una potestad ilimitada, y ni siquiera una facultad susceptible solamente de limitaciones administrativas, sino pura y simplemente una facultad ejercitable tan sólo dentro del marco en que aquella Ley y los correspondientes planes la configuren ${ }^{6} \gg$.

La Sentencia 7 de noviembre de 1977 contiene la siguiente doctrina:

«La ordenación urbanística objeto de la citada Ley del Suelo..., viene a constituir un sistema unitario y jerárquico de ámbitos normativos, que, de modo prospectivo y racional, comunica juridicidad a contenidos de reglas técnicas de urbanización y edificación de praxis variables en función en las concretas circunstancias de cada espacio de promoción urbana, lo que configura la susodicha ordenación como sistema jurídico de normas técnicas adscritas a planes, proyectos y programas que, aún tendentes a la máxima concreción, mantengan un sentido de generalidad normativa capaz de garantizar y coordinar el subjetivo y libre ejercicio de facultades dominicales con el interés público, afectante a todo el territorio nacional, en producir la mejora de la ciudad de modo integrado en el sistema que el planeamiento implica; normativa aquélla que adquiere su último grado de expresión específicamente, supuesto el régimen de ordenación planificada, en virtud de la licencia rectora del singular hecho constructivo, que al par que integra la concreta edificación en el sistema unitario del planeamiento, actúa como límite definidor del ejercicio por el administrado del 'ius aedificandi ${ }^{\prime}{ }{ }$.

La más reciente jurisprudencia del Tribunal Supremo integra, con una llamativa continuidad argumental, la precedente doctrina:

«...los Planes perfilan la ordenación territorial en atención a las demandas del interés público, siendo de notar que tal ordenación delimita, a su vez, el derecho de propiedad, al implicar de modo directo la clasificación y calificación del suelo al estatuto jurídico de la propiedad, de acuerdo con lo dispuesto en los artículos 76 y 87.1 de la citada Ley del Suelo de 1976 (RCL 1976, 1192). Este carácter estatutario de la propiedad inmobiliaria determina que el contenido y modalidades de la misma habrá de ser el emanado de la ordenación urbanística, cuya variación o modificación no puede ser obstaculizada por los derechos de los propietarios — artículo 87 de la Ley del Suelo-

5 Ponente Mg. Sr. Gordillo García, AZ 4505.

6 Ponente Mg. Sr. Martín Del Burgo, AZ 3358.

7 Ponente Mg. Sr. Ponce de LeÓn y Belloso, AZ 4377. 
aunque, en su caso, puedan dar origen a indemnización en los supuestos expresados en el precepto acabado de citar. Tal «ius variandi», precisamente respecto de la atribución al suelo de la cualidad de urbanizable o no urbanizable, esta caracterizado por la discrecionalidad en su determinación, aunque ésta en ningún caso puede ser producto de la arbitrariedad — artículo 9.3 de la Constitución (RCL 1978, 2836) - , estando sometida tal clasificación a las exigencias de racionalidad en estrecha conexión con el interés público» (Ant. Hecho 1. a, STS 19 de mayo de 2008; Pte. Mg. Sr. Calvo RoJas, JUR 2008\176292).

La jurisprudencia de la Sala de lo Contencioso de Málaga integra con convicción los Planes Urbanísticos en el concepto de Derecho Urbanístico:

«Se ha definido el Derecho Urbanístico como el conjunto de reglas a través de las cuales la Administración, en nombre de la utilidad pública, y los titulares del derecho de propiedad, en nombre de la defensa de los intereses privados, deben coordinar sus posiciones y sus respectivas acciones con vistas a la ordenación del territorio. Así en el tema urbanístico estarían implicados varios intereses por una parte los generales que ha de tutelar la Administración y, de otra, los particulares de los que, por regla general, son titulares los propietarios.

Se trata pues de una rama del Derecho Administrativo cuyas normas tienen por objeto el régimen del suelo, la ordenación del territorio, la transformación del medio y la protección de los derechos y deberes de los sujetos afectados.

Este Derecho no está integrado exclusivamente por las leyes reguladoras del régimen del suelo sino también por los planes urbanísticos aprobados en aplicación de aquéllas, teniendo especial relevancia dentro de sus fuentes las Ordenanzas Locales expresión natural de la capacidad normativa de las Corporaciones Locales» (STSJAnd 11 mayo 2007, Cont. Admvo, F. Jco. 4, Pte. Mgtda. Sra. Cardenal GómeZ, 2007 1822) ${ }^{8}$.

\section{El requisito de la publicación para la vigencia de los Planes de Urbanismo}

En contraste con la dinámica de otorgar licencias sin cobertura en un Plan y, en su lugar, pretender justificarlas en un Plan que se consideraba pendiente de aprobación, la doctrina del Tribunal Supremo era muy precisa con anterioridad al inicio de esta desviada práctica del Ayuntamiento de Marbella.

«la actuación municipal debe acomodarse a lo dispuesto en la Ley del Suelo, como norma específica aplicable a las licencias de obras concedidas en base a dicha normativa especial, y a tenor del artículo 56 de dicha Ley, los Planes serán inmediatamente ejecutivos, una vez publicada su aprobación definitiva, pero no antes, ya que la apro-

8 Dictada en recurso en contra del Acuerdo de la Comisión de Gobierno del Ayuntamiento de Marbella de fecha 12 de noviembre de 1999 y 21 de enero de 2000, con pendencia judicial de siete años y seis meses. 
bación inicial de los mismos sólo produce en su caso la suspensión del otorgamiento de licencias, con arreglo a lo dispuesto en el artículo 27 de la misma norma legal ...por no constituir todavía normativa urbanística aplicable y ejecutable, ya que sólo podía adquirir dicho carácter una vez aprobado dicho Plan definitivamente y debidamente publicado (STS 31 octubre 1988, Cont. Admvo, F. Jco 3. ${ }^{\circ}$ S. apelada, Pte. Mg. Sr. ESTEBAN ÁLAMO, RJ 1988\8360)».

«los parámetros de parcelación a aplicar en la zona unifamiliar del sector consolidado de ....aprobados por el Acuerdo plenario de ...no consta que hayan sido publicados con anterioridad a la producción de los actos impugnados, motivo que impedía su ejecutividad y, por tanto, su aplicación al caso de la actora... Este anormal proceder del Ayuntamiento..., conlleva necesariamente la precisión de no tener por vigentes y ejecutivos a los repetidos parámetros, al suponer una modificación del Plan General llevada a efecto sin seguir el procedimiento reglado y aprobada por un órgano totalmente incompetente, con su inevitable consecuencia de provocar la nulidad de los acuerdos municipales impugnados al denegar una licencia que conforme al Plan hubiera debido ser concedida... (STS 24 diciembre 1991, Cont. Admvo, F. Jco 1. ${ }^{\circ}$, Pte. Mg. Sr. BARRIO IGLESIAS, RJ 1992\372)».

\section{La Jurisprudencia de la Sala de lo Contencioso Administrativo de Málaga integra la doctrina del Tribunal Supremo:}

«Como el Tribunal Supremo ha precisado en diversas sentencias (por todas, la de 14 de abril de 1993 [RJ 1993, 2837]) "las licencias urbanísticas constituyen un acto debido en cuanto que necesariamente deben otorgarse o denegarse según que la adecuación pretendida se adapte o no a la ordenación aplicable. Va de suyo que la ordenación ha de estar vigente lo que dada la naturaleza normativa de los Planes exige no sólo que haya culminado su tramitación a través de la aprobación definitiva, sino que se haya producido su publicación, artículos 9.3 de la Constitución Española (RCL 1978, 2836); 45 y 46 Texto Refundido de la Ley del Suelo (RCL 1976, 1192) y hoy muy especialmente el artículo 70. 2 de la LRBRL de 7 de abril de 1985 (RCL 1985, 799, 1372)" (SsTSJAnd 26 enero 2004 y 28 noviembre 2004, Cont. Admvo, F. Jco 7. ${ }^{\circ}$ y F. Jco. 6. ${ }^{\circ}$, Pte. Mgtda.

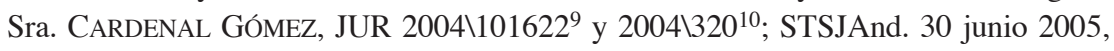
Cont. Admvo. F. Jco. 3. ${ }^{\circ}$, Mgtda. Sra. Gómez PASTOR, JUR 2005\14867311)».

«La S.T.S. de 9 de octubre de 1999 (por todas) muy contundentemente expresa: "Ciertamente que la exigencia de publicación en el Boletín Oficial de la provincia se refiere exclusivamente al articulado de las normas urbanísticas de los planes, como declara la jurisprudencia de esta Sala (Sentencias, entre otras, de 10 de abril de 1990, 9 de

\footnotetext{
9 Dictada contra Acuerdo de la Comisión de Gobierno del Ayuntamiento de Marbella de 23 de diciembre de 1999, con pendencia procesal de 4 años y 11 meses.

10 Dictada contra Acuerdo de la Comisión de Gobierno del Ayuntamiento de Marbella de 3 de octubre de 1997, con pendencia procesal de 7 años.

11 Dictada contra Acuerdo de la Comisión de Gobierno del Ayuntamiento de Marbella de 12 de febrero de 1999 , con pendencia procesal de 6 años y 4 meses.
} 
julio de 1990, 11 de julio de 1991, 22 de octubre del mismo año y 12 de junio de 1995), pero no es menos cierto que el defecto de publicación no sólo obstaculiza la entrada en vigor de las normas urbanísticas no publicadas sino que, además, impide la eficacia del Plan General de Ordenación Urbana en su integridad, ya que aquéllas son un elemento esencial del sistema o estructura del planeamiento urbanístico, por lo que el resto de sus determinaciones, ya sean gráficas o escritas, carecen de eficacia hasta tanto haya transcurrido el plazo fijado legalmente a partir de la publicación de las primeras, de manera que para la vigencia de las determinaciones combatidas en este proceso (urbanización del sector en cuestión y su ejecución por el sistema de expropiación) es imprescindible la publicación de las normas urbanísticas del Plan General que las prevé, y, en consecuencia, al declarar la Sala de instancia la nulidad del Plan Parcial de urbanización del sector y del proyecto de expropiación por ineficacia del primero, debido a la falta de publicación de sus normas urbanísticas, no ha vulnerado el precepto invocado como base de este motivo de casación, que por ello debe ser desestimado».

En expresa cita de la Sentencia del Tribunal Supremo de 3 de febrero de 1999, la Sala de lo Contencioso Administrativo de Málaga incide en esta cuestión con específicas precisiones sobre los efectos de la ausencia de cumplimiento del requisito de la publicación de los planes:

«La falta de publicación de un Plan de Urbanismo no le hace inválido, sino ineficaz. El artículo 45 de la antigua Ley de Procedimiento Administrativo (actual artículo 57 de la Ley 30/92, de 26 de Noviembre), es muy claro al respecto, pues prescribe que los actos administrativos son válidos desde la fecha en que se dictan, si bien su eficacia quedará demorada cuando está supeditada (...) a su publicación. Se trata, en consecuencia, de conceptos distintos: un acto puede ser válido pero puede no ser todavía eficaz si le falta la publicación, y la falta de ésta no significa la invalidez del acto, sino la imposibilidad de ejecutarlo, lo que es distinto. En el caso presente, la falta de publicación del Plan impedirá que la Administración lo imponga a los particulares (los cuales, en su caso podrán impugnar el acto de aplicación basándose precisamente en la falta de publicación del Plan), pero no producirá su invalidez.

Por lo demás, ninguna disposición obliga a que la publicación se ordene en la misma norma o acto que ha de ser publicado.

El problema no varía en absoluto si consideramos el Plan urbanístico como una disposición de carácter general y no como un acto administrativo, ya que el artículo 29 de la Ley de Régimen Jurídico de la Administración del Estado de 26 de Julio de 1957 (a la sazón vigente) se deduce que la falta de publicación de las disposiciones administrativas origina su ineficacia, y no su invalidez, pues tal precepto exige la publicación de las normas sólo «para que produzcan efectos jurídicos de carácter general».

«Y más recientemente la de 24 de enero de 2002 insiste en que "Ninguna duda existe sobre la necesidad de publicación de las normas urbanísticas de los Planes, o sobre la conexión evidente de este requisito formal con el artículo 9.3 de la Norma Fundamental. Existe, ya a principios del siglo pasado, doctrina clásica que ha sosteni- 
do con autoridad la equivalencia de valor de todos los momentos que componen el proceso de elaboración de una norma, de donde derivada, como consecuencia, la naturaleza constitutiva de la publicación que defiende la parte recurrente. Este Tribunal se viene orientando sin embargo por la configuración, de origen aún más antiguo, de la publicación como simple «conditio iuris» de la eficacia de la norma sometida a este requisito (sentencias de 30 de junio y 10 de abril de 2000, 30 de octubre, 20 de mayo, 3 de febrero y 21 de enero de 1999 y 18 de junio de 1998, por citar sólo algunas de las más recientes). Es indudable, en todo caso, que la publicación formal y necesaria determina la entrada en vigor de la norma publicada, y así se viene exigiendo en la jurisprudencia que se cita en el motivo, para las ordenanzas y disposiciones de todos los planes de urbanismo que participan de la naturaleza de norma jurídica, conforme al artículo 70.2 de la Ley 7/1985 antes y después de su reforma por la Ley 39/1994, de 30 de diciembre (últimamente en las sentencias de 20 de septiembre y 30 de junio de 2000), siendo pertinente precisar que consideramos que dicho precepto tiene funda-

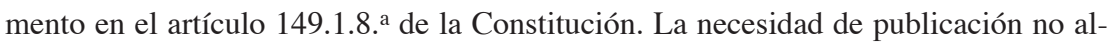
canza a los demás documentos o elementos que forman parte del Plan siempre que no sea normas ni participen de su naturaleza, como planos, gráficos o textos no normativos." Y la de 3 de diciembre de 2001 en cuanto a la unidad del Plan concreta «El Plan es único aunque se componga de distintos elementos, porque todos ellos coadyuvan a la misma finalidad de ordenación del ámbito territorial a que se refieran. No cabe aceptar, por tanto, que junto a las determinaciones de un nuevo plan mantengan su vigencia las del derogado por él. Normas Urbanísticas y Planos de ordenación no son elementos estancos, aunque tampoco estos últimos son simple expresión gráfica de lo indicado en la normativa urbanística. Con independencia de las normas urbanísticas los planos no tienen virtualidad alguna. Unas y otros son elementos imprescindibles para que el Plan tenga existencia, y la falta de publicación de las Normas Urbanísticas condiciona la vigencia entera del Plan. Por eso la entera vigencia del Plan queda condicionada a la completa publicación de sus normas en el Boletín Oficial que corresponda.

De esta forma no pudiendo admitirse en un Plan General la publicidad limitada al texto del acuerdo de aprobación definitiva, por no permitir éste el conocimiento de las normas de planeamiento por sus destinatarios ni satisfacer el principio de seguridad jurídica, hemos de negar, por la falta de íntegra publicación de la normativa del P.G.O.U. de Marbella de 1986, que dicho instrumento de planeamiento pudiera constituir el soporte legal de la licencia otorgada...» (SsTSJAnd 24 septiembre 2005 y 3 marzo 2007, Cont. Admvo, Fs. Jcos 4. ${ }^{\circ}$ y 6. ${ }^{\text {a }}$, Pte. Mgtda. Sra. CARdenAl GómEZ, JUR $2005 \backslash 159210^{12}$ y $\left.2007 \backslash 29816^{13}\right)$.

El completo análisis del marco jurídico realizado por la jurisprudencia de la Sala se proyecta en la casuística de las licencias otorgadas para promociones

12 Dictada contra Acuerdo de la Comisión de Gobierno del Ayuntamiento de Marbella de 17 de julio de 1998, con pendencia procesal de 8 años y 2 meses.

13 Dictada contra Acuerdo de la Comisión de Gobierno del Ayuntamiento de Marbella de 26 de junio de 1998, con pendencia procesal de 7 años y 9 meses. 
inmobiliarias, Sentencias en las que se puede apreciar el largo periodo temporal trascurrido entre la adopción del acuerdo del Ayuntamiento de Marbella de concesión de licencia y la fecha de pronunciamiento de la Sentencia, con el resultado de materializar los efectos de la licencia, singularizada en la conclusión de la edificación, con la secuela de una problemática ejecución de los fallos de las Sentencias aun resolviendo su ilegalidad.

«En la Sentencia de 23 de octubre de 2003, dictada con ocasión del recurso presentado en contra de la licencia otorgada en 1998 por la Comisión de Gobierno del Ayuntamiento de Marbella, por la que se autorizaba la construcción de tres bloques de apartamentos, en sustitución de la previsión del Plan de 1986 de construcción de viviendas unifamiliares exentas, recurrida por una sociedad mercantil, la Sala recuerda el vínculo de la licencia con el principio de legalidad que predetermina que la Administración solo puede hacer aquello para lo que se encuentra autorizada; el contenido del derecho de propiedad ejercitado "dentro de los límites y en cumplimiento de los deberes» establecidos por el ordenamiento urbanístico; que la licencia urbanística es de una rigurosa naturaleza reglada, que constituye un acto debido que necesariamente 'debe' otorgarse o denegarse según que la actuación pretendida se adapte o no a la ordenación aplicable; que el la «propiedad inmobiliaria" sometida a la legislación urbanística y de naturaleza estatutaria significa que el titular puede hacer aquello para lo que está previa y expresamente habilitado. Precisa que la "normativa" u "ordenación" urbanística aplicable, requiere que los Planes deben ser íntegramente publicado en el Boletín Oficial correspondiente y que sus efectos se producen desde la fecha de publicación, y que la validez o invalidez de las licencias no se resuelve conforme a normas de planeamiento futura sino conforme a las normas de planeamiento que resulten aplicables en el momento de su concesión en vía administrativa.»

Sobre el conjunto de principios expuestos, el pronunciamiento de la Sentencia es preciso:

«la licencia se ha otorgado sin someterse a ningún planeamiento vigente» $\mathrm{y}$, en lógica consecuencia «vulnerando el ordenamiento jurídico directa e inmediatamente aplicable, por lo que debemos entenderla contraria a derecho y anularla de acuerdo con el artículo 63 de la Ley 30/1992» (F. Jco 4. ${ }^{\circ}$ Pte. Mg. Sr. GARCía Bernaldo DE QuiRÓs, JUR 2003\265113 ${ }^{14}$ ).

La Sentencia de 14 de enero de 2004 resuelve el recurso formalizado contra el acuerdo de la Comisión de Gobierno del Ayuntamiento de Marbella de 13 de marzo de1998, por el que se autorizó la construcción de cuatro edificios, objeto de recurso por la Junta de Andalucía, reitera la vigencia del principio de vinculación positiva a la legalidad de la actuación administrativa; el contenido estatutario de la propiedad inmobiliaria y el vínculo de su titular a lo que está previa y expresamente habilitado; el otorgamiento de las licencias, a diferencia de las

14 No consta fecha de acuerdo de la Comisión de Gobierno, con referencia en la identificación del recurso contencioso administrativo n. ${ }^{\circ}$ 4014/1998, computables 5 años de pendencia judicial. 
autorizaciones, para una operación singular y concreta, y conforme a las normas de planeamiento que le son de aplicación; el condicionamiento del ejercicio de concesión de la licencia por el Ayuntamiento a un control de legalidad conforme a la «normativa urbanística aplicable». Reitera que para la eficacia de las normas de los Planes de Urbanismo deben ser íntegramente publicadas en el Boletín Oficial correspondiente, y que la validez de la licencias no se resuelve conforme a normas de planeamiento futuras sino conforme a las normas de planeamiento que resulten aplicables a las mismas en el momento de su concesión en vía administrativa, recuerda el tenor literal del artículo 320 del Código Penal, y considera «totalmente desafortunada la conducta municipal» que considera que la licencia no se ajusta al planeamiento existente porque no estaba publicado y estima que no es aplicable en el futuro, que ni se encuentra aprobado ni publicado, afirmación del Ayuntamiento que para la Sentencia «solo puede significar una cosa: no ha existido un control de la legalidad urbanística respecto de la petición realizada, puesto que la Administración (local) entre dos planes ineficaces escoge uno que es tan ineficaz como el otro, rechazando el que, al menos, se encuentra aprobado».

\section{La Sentencia concluye:}

«En cualquier caso, la licencia se ha otorgado sin someterse a ningún planeamiento vigente. Y, en lógica consecuencia, vulnerando el ordenamiento jurídico directa e inmediatamente aplicable, por lo que debemos entenderla contraria a derecho y anularla de acuerdo con el artículo 63 de la Ley 30/1992» (F. Jco 5.ํ. Pte. Mgtda. Sra. GómEZ PASTOR, JUR 2004\69256 ${ }^{15}$ ).

La Sentencia de 30 de noviembre de 2005, resuelve el recurso de la Junta de Andalucía contra la licencia otorgada el 26 de julio de 1998 por la Comisión de Gobierno del Ayuntamiento de Marbella, que autorizó la construcción de 12 viviendas adosadas, con una edificabilidad de $0,69 \mathrm{~m}^{2} / \mathrm{m}^{2}$, y que contraviene lo previsto en el Plan General de Ordenación Urbana de 1986 que preveía una altura máxima de $\mathrm{PB}+1$ con una tipología de vivienda unifamiliar exenta. La Sentencia califica el acuerdo de concesión de licencia como nulo de pleno derecho y aprecia:

«...entrando a conocer sobre el alegado por la parte recurrente sobre el fondo del recurso y que según se dijo estriba en entender que el acuerdo de concesión de la licencia de obras es nulo de pleno derecho al contravenir el planeamiento vigente al autorizarse una obra con una altura superior a la permitida y posibilitando la construcción de doce viviendas adosadas cuando la tipología autorizada es de vivienda unifamiliar exenta, y en todo caso y si así no se entendiese, sería constitutivo de infracción urbanística grave lo que arrastraría la anulabilidad del acuerdo, el mismo ha de ser acogido pues visto que con arreglo al planeamiento vigente las condiciones para la edificabili-

15 Dictada contra Acuerdo de la Comisión de Gobierno del Ayuntamiento de Marbella de 13 de marzo de1998, con pendencia procesal de 6 años. 
dad no permitían la concesión de la licencia otorgada ya que esta en definitiva al alterar no sólo la altura sino el tipo de viviendas aumentaba el volumen de edificabilidad autorizado por el planeamiento, el acuerdo deviene nulo, sin que a ello puede oponerse ni el hecho alegado por la parte recurrida relativo a que la falta de publicación del plan general de 1986 la licencia fue concedida en base a la revisión del plan aprobado provisionalmente por la Corporación Municipal y, en base a la cual, se resolvió un convenio urbanístico con la entidad a la que le fue concedida la licencia de obras pues, por un lado y como razona la parte demandante, no sólo resulta contrario a la buena fe el alegar la falta de eficacia como consecuencia de la no publicación del plan por parte de quien tenía la obligación de publicarlo, sino que, además y lo que es más importante, al no constar que la revisión del plan en base a la cual se suscribió el convenio y se otorgó la licencia, haya sido aprobado definitivamente, pues la aprobación que por silencio alega el Ayuntamiento ha sido impugnada en sede jurisdiccional encontrándose pendiente de resolución, no puede conferirle el valor que la parte alega pues ello presupondría dar mayor valor a un acto que no ha sido aprobado definitivamente sobre un acto que aún aprobado con tal carácter no ha sido publicado, o dicho en otros términos dar mayor eficacia a un acto invalido sobre otro válido pero ineficaz; y sin que por último sea dable argüir la eficacia y validez del convenio suscrito ...pues sin desconocer la posibilidad de la suscripción de convenios urbanísticos con el alcance como el que se discute, al ser lo cierto que la validez de los mismos penden de la del plan del que traen causa así como que no pueden contravenir sus disposiciones, no puede sino desestimarse el motivo» (F.Jco. 2. ${ }^{a}$, Pte. Mg. Sr. DE LA TORRE DEZA, JUR 14754716).

La Sentencia de 11 de octubre de 2005 resuelve el recurso formalizado por la Junta de Andalucía en contra del acuerdo del Ayuntamiento de Marbella de 2 de octubre de 1998, por el que se autorizó a una sociedad mercantil que posteriormente transmitió a otra sociedad mercantil, la construcción de un edificio de PB+9+Ático, cuando conforme al PGOU de Marbella de 1986 la altura prevista es $\mathrm{PB}+5$ o 19 metros de altura. La Sentencia resuelve:

«...entrando a conocer del fondo del recurso, el mismo ha de ser estimado y ello porque constando que la licencia impugnada fue concedida al amparo de la revisión del plan general aprobado por la Corporación Municipal por silencio administrativo el 7 de Agosto de 1998, y teniendo en cuenta que dicha revisión no había sido aprobada por la Comisión Provincial de Urbanismo a la par que su ejecución quedó suspendida por auto de la Sala dictado en el recurso 2399/98 a excepción de las licencias concedidas con anterioridad, no puede sino concluirse lo indicado, sin que por tanto sea dable admitir el razonamiento de las codemandadas, relativo a la falta de validez y aplicación del plan de 1986 por no estar debidamente publicado, pues sin entrar a reconocer sobre tal particular, al menos con la intensidad propia del objeto propio de un proceso, y como razona la parte demandante no es razonable ni admisible ampararse en la falta de publicación como elemento negador a la aplicabilidad del plan y ampararse en una

16 Dictada contra Acuerdo de la Comisión de Gobierno del Ayuntamiento de Marbella de 26 de julio de 1998, con pendencia procesal de 7 años. 
revisión posterior que ha sido ni siquiera aprobada por la Comisión Provincial de Urbanismo, pues actuando así se daría preferencia a un acto en apariencia inválido sobre un acto en apariencia válido pero ineficaz, no oponiéndose a ello ni el invocado ius variandi de la administración en cuanto al planeamiento pues sin desconocer dicho derecho, el mismo no permite quebrantar la legalidad en cuanto a los requisitos establecidos para la vigencia de los planes de urbanismo y menos adelantar los efectos derivados de la aprobación de un plan a actos realizados con anterioridad a la misma, por todo lo cual procede estimar el recurso interpuesto» (F.Jco. 3, Pte. Mg. Sr. DE LA TORRE DEZA, JUR 2005|148216 ${ }^{17}$ ).

La Sentencia de 28 de julio de 2006, resolutoria del recurso formalizado por la Junta de Andalucía, en contra del acuerdo de la Comisión de Gobierno del Ayuntamiento de Marbella de 16 de octubre de 1999, por el que se autoriza la construcción de 21 viviendas adosadas y 16 viviendas pareadas, con fundamento en que se proyectan sobre una superficie en la que, conforme al Plan de 1986, incorpora parte de vivienda adosada, parte de equipamiento deportivo privado y sistema general de comunicaciones. La Sala resuelve:

«...entrando a conocer del fondo de la cuestión que se debate y que no es otra que determinar si la licencia impugnada incurre en la causa de nulidad invocada por la recurrente al amparo de lo dispuesto en el art. 62-1-e de la ley 30/92 en relación con la Ley 1/97 de 18 de junio de Andalucía; al otorgarse una licencia de obras para la construcción de 21 viviendas adosadas y 16 viviendas pareadas en la PA-SP-2 del PGOU de Marbella de 1.986 y ello por contravenir el planeamiento vigente en cuanto que parte de la parcela se encuentra calificada de unifamiliar adosada y parte de equipamiento deportivo privado incluyendo además terrenos del sistema general de comunicación SG-C-6 carretera de Estepona, el mismo ha de ser acogido pues constando que los terrenos para los cuales se obtuvo la licencia según aparece documentado en los folios 3 y 19, se encuentran calificados según relata la parte recurrente no puede sino estimarse el motivo sin que a ello se opongan las razones invocadas de contrario pues en orden a la inaplicabilidad del plan de 1986 por no haber sido objeto de publicación y aun cuando se pudiera entender su inaplicabilidad en ningún caso ello autoriza a tener por vigente la revisión del mismo del año 1998 pues no ello conllevaría la necesidad de dar preferencia a un plan aún no aprobado sobre un plan aprobado pero no publicado, interpretación ésta que por absurda está vedada en derecho, sino porque además no es amparable en derecho, y ello por ser contrario a la buena fe que la eficacia de un planeamiento que la parte reconoce cuando actúa concediendo licencias, sea negada por ésta cuando el acto es impugnado, y además porque en todo caso y aún cuando se admitiese lo razonado por dicha parte en cuanto a la falta de vigencia del plan de 1986 por cuanto que el plan a aplicar sería el de 1.968, siendo así que al constar con arreglo a éste que las parcelas sobre las cuales se otorgó la licencia impugnada se encontraban clasificadas como terreno rústico y falto de un plan especial que autoriza-

17 Dictada contra Acuerdo de la Comisión de Gobierno del Ayuntamiento de Marbella de 2 de octubre de 1998, con pendencia procesal de 7 años. 
se la construcción que se discute así como la necesaria autorización de la Comisión Provincial de Ordenación del Territorio y Urbanismo, concurría causa de nulidad, lo que a su vez conllevará la estimación del recurso» (F. Jco. 3, Pte. Mg. Sr. DE LA TORRE DEZA, JUR 2006\30895'18).

La Sentencia de 14 de julio de 2007, dictada en recurso formalizado por la Junta de Andalucía, en contra del Acuerdo del Ayuntamiento de Marbella de 18 de septiembre de 1998, por el que se autoriza la construcción de dos bloques de 64 viviendas, con la superación de la previsión del Plan de 1986 de PB+6+Ático (8 plantas) por $\mathrm{PB}+7+$ Ático (9plantas), con incorporación de los mismos argumentos expresados en la precedente Sentencia de 14 de enero de 2004, de modo sumario, resuelve:

«En cualquier caso, la licencia se ha otorgado sin someterse a ningún planeamiento vigente. $\mathrm{Y}$, en lógica consecuencia, vulnerando el ordenamiento jurídico directa e inmediatamente aplicable, por lo que debemos entenderla contraria a derecho y anularla» (F. Jco. 7. $^{\circ}$, Pte Mgtda. Sra. GómEZ PASTOR, JUR $78258^{19}$ ).

Los ponderados fundamentos jurídicos de la Sala de lo Contencioso Administrativo de Málaga contrastan con la progresiva acumulación de anualidades entre las fechas de los acuerdos municipales y las fechas de las Sentencias, de tal modo que los cinco años iniciales entre el acto municipal y la Sentencia en el control de las licencias se prolongan a los nueve años. En contraste con la cualificada jurisprudencia de la Sala, la actuación jurisdiccional realizada en el menor tiempo, cinco años, permite apreciar que la edificación puede estar concluida en la cuarta parte de ese periodo temporal, con la consecuente consolidación de la vía de hecho y con la estratégica integración de decenas de terceros de buena fe, que otorgan plena validez a la ineficacia del sistema jurídico, en calidad de justificado basamento operativo para los mentores de las actuaciones municipales ilegales.

\section{Los Planes vigentes determinan el contenido reglado de la licencia}

Con referencia temporal en la jurisprudencia del Tribunal Supremo del año 1983 se constata la existencia de una doctrina consolidada y una afinada conceptualización de la licencia urbanística:

«es reiterada la jurisprudencia en la que se proclama que el otorgamiento de las licencias de obras debe de ajustarse a la normativa vigente en el momento en que son

\footnotetext{
18 Dictada contra Acuerdo de la Comisión de Gobierno del Ayuntamiento de Marbella de 16 de octubre de 1999, con pendencia procesal de 7 años.

19 Dictada contra Acuerdo de la Comisión de Gobierno del Ayuntamiento de Marbella de 18 de septiembre de 1998, con pendencia procesal de 9 años.
} 
interesadas -SS. 11 noviembre 1971 (RJ 1971\4415), 12 junio 1972 (RJ 1972\3492), 28 septiembre 1973 (RJ 1973\3457), 21 noviembre 1974 (RJ 1974\4995), 15 enero 1976 (RJ 1976\476), 16 enero 1978 (RJ 1978\159), 23 febrero y 6 marzo 1979 (RJ $1979 \backslash 695$ y RJ 1979\1073) y 20 mayo 1980 (RJ 1980\2817) -, pues el otorgamiento de licencias es una actividad reglada sin que, en consecuencia, se pueda denegar una licencia de construcción, si ésta no contraría las normas existentes sobre planeamiento urbanístico, que como es lógico deben de estar vigentes en el momento en que se solicita la licencia» (STS 28 diciembre 1983, Cont. Admvo, Cdo. 7. ${ }^{\circ}$ S. apelada, Mg. Pte. Sr. MARTín MARTíN, RJ 1983\6860)

«La licencia municipal, cuya naturaleza jurídica ha sido precisada con toda claridad por la Jurisprudencia como acto de control preventivo, no es constitutiva, sino meramente declarativa de un derecho preexistente del administrado ya atribuido por el ordenamiento urbanístico y por el derecho civil, que no transfiere facultades, sino que remociona límites, por lo que su otorgamiento o denegación se ha de efectuar dentro de la más estricta legalidad, pues la Administración no es libre para decidir si otorga o no la licencia, puesto que el contenido del acto ha de ser por entero reglado, lo que impide establecer restricciones discrecionales en cuanto que el contenido del acto no depende del libre arbitrio o de la discrecionalidad de la Administración, pues ésta ha de actuar vinculada a los dictados de las normas y de los Planes operantes en cada caso».../...

«...el pronunciamiento de la referida Sala es conforme a Derecho, dado que el art. 83 de la Ley Jurisdiccional le obligaba a estimar el recurso si los actos incurrían en cualquier forma de infracción del ordenamiento jurídico, pues en definitiva la estimación o desestimación del recurso depende única y exclusivamente de que el acto o disposición impugnados no se adecuen o se ajusten, respectivamente, al ordenamiento aplicable que en el presente caso venía constituido por el Plan Parcial..., aprobado..., por lo que resultaba absolutamente improcedente contrastar la actuación urbanística pretendida por los interesados con una documentación que no formaba parte integrante de dicho Plan. Interesa, no obstante, precisar en relación con la supuesta ignorancia o conocimiento equivocado de la documentación urbanística aplicable por parte del Ayuntamiento apelante, que el propio Arquitecto Municipal había informado ya ...del expediente administrativo - , y por tanto con anterioridad a todos los actos impugnados en el Recurso..., que la licencia no podía concederse hasta tanto la Comunidad Autónoma de Madrid no se pronunciara sobre si los planos obrantes en el Ayuntamiento se correspondían o no con los aprobados en su día para el Plan Parcial, por lo que resulta, cuando menos, incongruente pretender ahora acogerse a un erróneo conocimiento de la documentación aplicable, cuando los propios servicios técnicos municipales habían advertido sobre la improcedencia de ningún tipo de pronunciamiento mientras no se determinara la ordenación urbanística realmente aprobada» (STS 4 octubre 1983, Cont. Admvo, F.Jco. 3. ${ }^{\text {a }}$, S. apelada y F.Jco. 2. ${ }^{\circ}$, TS), Mg. Pte. Sr. DE Oro. PULIDO Y LÓPEZ, RJ 1993\7343)

La Sala de lo Contencioso Administrativo de Málaga, en el marco doctrinal de la jurisprudencia del Tribunal Supremo, aprecia: 
«...En efecto ni la Sala, ni las propias partes en sus alegaciones, han podido encontrar, de forma clara y ostensible a los efectos del enjuiciamiento cautelar, el respaldo de la licencia en normas del Plan que, sin perjuicio del enjuiciamiento pormenorizado que se pudiera haber hecho en sentencia, permitan deducir el ajuste al planeamiento de la licencia cuestionada. Como el Planeamiento es una competencia también de la Comunidad Autónoma el interés de ésta ha exigido el mantenimiento de la medida acordada.»

«Aplicando lo anterior a caso de autos tenemos que la licencia no se encuentra amparada por Plan General o norma de desarrollo que habilite la construcción de lo autorizado. (STSJAnd de 30 de junio de 2006, F. Jco. 4. ${ }^{\circ}$, Mg. Sr. García Bernaldo de Quirós, JUR 2007\78669 ${ }^{20}$ ).»

La consolidación de la doctrina, en contraste con la contumacia en sus desviadas prácticas por el Ayuntamiento de Marbella, conduce a enunciados sintéticos en algunas Sentencias de la Sala de lo Contencioso de Málaga:

«Como el Tribunal Supremo ha precisado en diversas sentencias (por todas, la de 14 de abril de 1.993) «las licencias urbanísticas constituyen un acto debido en cuanto que necesariamente deben otorgarse o denegarse según que la adecuación pretendida se adapte o no a la ordenación aplicable. Va de suyo que la ordenación ha de estar vigente lo que dada la naturaleza normativa de los Planes exige no sólo que haya culminado su tramitación a través de la aprobación definitiva, sino que se haya producido su publicación, artículos 9. 3 de la Constitución Española; 45 y 46 Texto Refundido de la Ley del Suelo y hoy muy especialmente el artículo 70. 2 de la L.R.B.R.L. de 7 de abril de 1.985» (STSJAnd23 enero 2004, Cont. Admvo., F. Jco. 3, Pte. Mg. Sr. LóPEZ AGULLÓ, JUR 2004\101423²1).

Los pronunciamientos de síntesis coexisten con enunciados argumentales más complejos, avalados por la voluntad de explicitar una contundente posición sincrética y descriptiva de la Sala:

«La licencia impugnada debe ser contemplada desde las siguientes premisas. Como todo acto administrativo producido por una Administración pública debe responder al principio de legalidad, en el sentido de entender que la Administración sólo puede actuar cuando la norma se lo permite. Es lo que se llama principio de vinculación positiva de la Administración. La Administración sólo puede hacer aquello para lo que se encuentra legalmente habilitada. Este principio general, que tiene reflejo constitucional en el artículo 103, cuando se proyecta sobre la concesión de licencias urbanísticas se encuentra aún más reforzado por la legislación específica. La licencia es un acto rigurosamente reglado que debe otorgarse necesariamente

20 Dictada contra Acuerdo de la Comisión de Gobierno del Ayuntamiento de Marbella de 19 de febrero de 2003, con pendencia procesal de 2 años y 4 meses.

21 Dictada contra Acuerdo de la Comisión de Gobierno del Ayuntamiento de Marbella de 7 de noviembre de 1997, con pendencia procesal de 7 años y 10 meses. 
cuando la petición de la misma reúne las condiciones fijadas por la norma para la actividad solicitada. Así lo ha entendido de forma reiterada el Tribunal Supremo. En efecto, para el citado Tribunal, "la licencia urbanística es un acto administrativo de autorización por cuya virtud se lleva a cabo un control previo de la actuación proyectada por el administrado, verificando si se ajusta o no a las exigencias del interés público urbanístico tal y como han quedado plasmadas en la ordenación vigente. Si es ésta la que determina el contenido del derecho de propiedad (art. 76 del Texto Refundido de la Ley del Suelo), es claro que este derecho ha de ejercitarse «dentro de los límites y en cumplimiento de los deberes" establecidos por el ordenamiento urbanístico. Licencia la examinada de rigurosa naturaleza reglada, que constituye un acto debido en cuanto que necesariamente "debe" otorgarse o denegarse según que la actuación pretendida se adapte o no a la ordenación aplicable» (SSTS, Sala 3. a , Sección $1 .^{\text {a }}$, de 8 julio, 22 septiembre, 16 octubre y 13 noviembre 1989 y 29 enero 1990, y de 6 mayo 1998).

«Por otra parte, la propiedad inmobiliaria sometida a la legislación urbanística ha evolucionado hacia una propiedad de naturaleza estatutaria, que significa que el titular del derecho de propiedad puede hacer aquello para lo que está previa y expresamente habilitado. Así se desprende de todo el conjunto de la legislación urbanística existente en el territorio nacional y esta característica está identificada por el Tribunal Supremo, entre otras muchas, en la siguiente sentencia cuando afirma lo siguiente: « Las licencias de obras, a diferencia de las autorizaciones que implican autorizaciones de funcionamiento, se conceden para una operación singular y concreta, conforme a las normas de planeamiento que le son de aplicación. Exigen por ello una apreciación por parte de la Administración autorizante de la realidad del estado de cosas que existe en el momento en que se debe otorgar, para determinar si la misma se acomoda o no a las normas establecidas para garantizar el interés público, que justifica la sumisión a un control «ex ante» del acto de que se trata» (Sentencia Tribunal Supremo (Sala de lo Contencioso-Administrativo, Sección 5. a), de 21 febrero 2000).

Remisión de la licencia a un control de legalidad por parte del Ayuntamiento, titular de esta potestad de concesión, que debe hacerse a lo que se denomina «normativa urbanística aplicable». Pues bien, sobre cuál debe ser la ordenación urbanística aplicable tenemos la siguiente doctrina jurisprudencial:

A) Para que sean eficaces las normas de los Planes de Urbanismo deben ser íntegramente publicadas en el Boletín Oficial correspondiente, tal como exige el artículo 70.2 de la Ley de Bases de Régimen Local de 2 de abril de 1985 (por todas, sentencias de 21 de enero de 1999, 3 de febrero de 1999 y 18 de junio de 1998).

B) Si la posterior publicación de las normas de un Plan se entiende como una convalidación, en el sentido del artículo 53 de la antigua Ley de Procedimiento Administrativo, sus efectos se producen desde la fecha de la publicación (artículo 53.3), salvo que se le puedan dar efectos retroactivos de conformidad con lo dispuesto en el artículo 45.3 de aquella Ley; pero para esa eficacia retroactiva se exige que ésta «no lesione derechos o intereses legítimos de otras personas», requisito que no se cumple 
en el presente caso en que la eficacia retroactiva de la convalidación se produciría en perjuicio de las demandantes de este recurso (que no impugnaron la licencia ejercitando la acción pública en materia de urbanismo, sino defendiendo evidentes intereses particulares). (Sentencia Tribunal Supremo (Sala de lo Contencioso-Administrativo, Sección 5.a), de 10 abril 2000).

C) La validez o invalidez de las licencias no se resuelve conforme a normas de planeamiento futuras sino, según jurisprudencia unánime, conforme a las normas de planeamiento que resulten aplicables a las mismas en el momento de su concesión en vía administrativa. Como se dijo en la STS de 4 de julio de 1997 las licencias urbanísticas son actos reglados que se otorgan conforme al planeamiento en vigor — bien sea éste el vigente en el momento de la solicitud o en el momento de la decisión-, pero nunca conforme a un planeamiento futuro. Las solicitudes de licencia no generan expectativas respecto del planeamiento futuro (Sentencia Tribunal Supremo (Sala de lo Contencioso-Administrativo, Sección 5. a), de 15 junio 2001. En el mismo sentido sentencias de 25 de mayo de 2001, 20 de octubre y 17 de abril de 1998, entre otras muchas).

Como vemos las licencias urbanísticas deben otorgarse conforme a las normas de tal naturaleza que le sean de aplicación. Normas que tienen que estar vigentes al momento de la petición o de la resolución, según los casos. Criterio de rigurosa temporalidad que no sólo se desprende de la legislación urbanística, Estatal o Autonómica, sino que incluso ha sido recogido por el Código Penal cuando en su artículo 320 cuando dice: «1. La autoridad o funcionario público que, a sabiendas de su injusticia, haya informado favorablemente proyectos de edificación o la concesión de licencias contrarias a las normas urbanísticas vigentes será castigado con la pena establecida en el artículo 404 de este Código y, además, con la de prisión de seis meses a dos años o la de multa de doce a veinticuatro meses.» $\mathrm{Y}$ hemos visto anteriormente que un planeamiento futuro nunca legitima la concesión de una licencia actual. O dicho de otra forma, no puede otorgarse una licencia contemplando sólo un futuro planeamiento» (Ss.TSJA, Cont. Admvo, 17 octubre 2003 y 23 octubre 2003, F. Jco. 3, Pte. Mg. Sr. Garcia Bernaldo de Quirós, JUR 2003\26510922, 2003\26511323 y 2003\26491724, item STSJA, Cont. Admvo, 14 enero 2004, F. Jco. 3, Pte. Mgtda. Sra. Gómez Pastor, JUR 2004\69256 ${ }^{25}$ y STSJA, Cont. Admvo, 15 abril 2004, F. Jco. 3, Pte. Mg. Sr. López Agulló, JUR 2004\162662²6).

\footnotetext{
22 Dictada contra Acuerdo de la Comisión de Gobierno del Ayuntamiento de Marbella de 29 de octubre de 1996, con pendencia procesal de 7 años.

23 Dictada contra Acuerdo de la Comisión de Gobierno del Ayuntamiento de Marbella de 28 de agosto de 1998, con pendencia procesal de 5 años.

24 Dictada contra Acuerdo de la Comisión de Gobierno del Ayuntamiento de Marbella de 12 de diciembre de 1997, con pendencia procesal de 5 años y 11 meses.

25 Dictada contra Acuerdo de la Comisión de Gobierno del Ayuntamiento de Marbella de 13 de marzo de 1998, con pendencia procesal de 6 años y dos meses.

26 Dictada contra Acuerdos de la Comisión de Gobierno del Ayuntamiento de Marbella de 9 de septiembre y 12 de octubre de 1998, con pendencia procesal 5 años y 6 meses.
} 


\section{El desconcertante pero justificado tránsito del no publicado Plan General de Ordenación Urbana de 1986 al precedente Plan General de Ordenación urbana de 1968}

Lo que, en principio, pudiera ser identificado con un error vinculado a la alteración del orden numérico, tiene que ser identificado con la oportuna valoración jurisdiccional de hechos concurrentes y normativa aplicable, que desplazó la dinámica urbanística del Ayuntamiento de Marbella, centrada en el Plan General de 1986, no publicado, a la elaboración de un nuevo Plan y que, en el argumentario del salto adelante, obliga a incorporar el retorno al único Plan que podía ser declarado vigente: el Plan General de 1968.

La Sentencia de 24 de septiembre de 2005, resuelve el recurso formalizado por la Asociación para la Protección y Defensa de la Urbanización Guadalmina, en contra de los acuerdos de la Comisión de Gobierno del Ayuntamiento de Marbella, de 17 de julio y 11 de diciembre de 1998, por la que se autorizó la construcción de 48 viviendas en relación con las 12 viviendas unifamiliares exentas que, conforme a certificación del Arquitecto Municipal autorizaba el Plan de 1986. La Sentencia constata que el Derecho Urbanístico está integrado por las leyes del régimen del suelo y por los planes urbanísticos aprobados en aplicación de aquellas, recuerda el carácter reglado de las licencias y aprecia que en el momento de otorgamiento de la licencia por la Comisión de Gobierno no había sido objeto de publicación el Plan General de Ordenación Urbana de Marbella de 1986, objeto de publicación en el BOP de Málaga de 28 de noviembre de 2000, motivo por el cual el Plan aplicable se defiere al Plan General de Ordenación Urbana de Marbella de 1968, y aporta el dato complementario de que el Auto de la misma Sala de 10 de septiembre de 1998, a instancia de la Junta de Andalucía declaró la suspensión de la ejecutividad del acuerdo del Pleno del Ayuntamiento de Marbella de 7 de agosto de 1998, referente a la aprobación de la Revisión del PGOU de Marbella, con la consecuencia de considerar que la clasificación de suelo conforme al Plan de 1968 es de Suelo Rústico de Control, con posibilidad de construcción de Vivienda Unifamiliar Aislada en parcela mínima de 4.000 metros, con un máximo de 6 viviendas unifamiliares aisladas, conjunto de circunstancias que obligan a resolver:

«...la Sala debe estimar el recurso y anular las licencias concedidas — anulación que afectará lógicamente a cuantos actos traigan causa de las mismas - no por su disconformidad con el PGOU de 1986, sino por ser contraria al de 1968 por lo que la parte dispositiva de esta sentencia contendrá el pronunciamiento que es de observar en la misma» (STSJAnd de 24 de septiembre de 2004, F. Jco. 6. ${ }^{\circ}$ Pte, Mgtda. Sra. Cardenal Gómez, JUR 2005\15921027).

27 Dictada contra Acuerdo de la Comisión de Gobierno del Ayuntamiento de Marbella de 17 de julio de 1998 , con pendencia procesal de 6 años y 2 meses. 


\section{La implicación penal de las licencias urbanísticas}

La referencia de las precedentes Sentencias de 17 y 23 de octubre de 2003 a preceptos penales, tiene complemento en las explícitas referencias de sucesivas Sentencias a los artículos 319 y 320 del Código Penal de 1995 y a la extrapolación de las tradicionales regulaciones administrativas de la actividad urbanística al ámbito penal, también objeto de oportuna puntualización por la doctrina de la Sala de lo Contencioso Administrativo de Málaga.

En las Sentencias de 14 de enero de 2004 y 14 de julio de 2007, se constata:

«Como vemos las licencias urbanísticas deben otorgarse conforme a las normas de tal naturaleza que le sean de aplicación. Normas que tienen que estar vigentes al momento de la petición o de la resolución, según los casos. Criterio de rigurosa temporalidad que no sólo se desprende de la legislación urbanística, Estatal o Autonómica, sino que incluso ha sido recogido por el Código Penal cuando en su artículo 320 cuando dice: «1. La autoridad o funcionario público que, a sabiendas de su injusticia, haya informado favorablemente proyectos de edificación o la concesión de licencias contrarias a las normas urbanísticas vigentes será castigado con la pena establecida en el artículo 404 de este Código y, además, con la de prisión de seis meses a dos años o la de multa de doce a veinticuatro meses.» Ya hemos visto anteriormente que «un planeamiento futuro nunca legitima la concesión de una licencia actual. O dicho de otra forma, no puede otorgarse una licencia contemplando sólo un futuro planeamiento» (STSJAnd de 14 de enero de 2004, F. Jc. $4 .^{\circ}$ y STSJAnd de 14 de enero de 2004, F. Jco. $6^{\circ}{ }^{\circ}$, Pte. Mgtda. Sra. GOMEZ PASTOR, JUR 2004\69256 ${ }^{28}$ y JUR $2007 \backslash 78258^{29}$ ).

Y en las Sentencias de 3 de marzo de 2006, de 12 de noviembre de 1999, 21 de enero de 2000 y 11 de mayo de 2007, se precisa:

«Es el propio Código Penal de 1995 (RCL 1995, 3170 y RCL 1996, 777) el que - aparte de la clara normativa urbanística aplicable recogida en la Ley de la Comunidad Autonómica 1/1997 (LAN 1997, 246) y demás normativa de aplicación como el Reglamento de Gestión Urbanística o de Disciplina urbanística o de Planeamiento Urbanística- viene a sancionar en su art. 319 a los promotores, constructores o técnicos directores que lleven a cabo una construcción no autorizada en suelos destinados a viales, zonas verdes, bienes de dominio público, de reconocido valor paisajístico, ecológico, artístico, histórico o cultural y el art. 320 del mismo texto legal castiga a la autoridad o funcionario público que, a sabiendas su injusticia, haya informado favorablemente «la concesión de licencias contrarias a las normas urbanísticas vigentes», así como a los que hayan «resuelto o votado a favor de su concesión a sabiendas de su injusticia» (STSJAnd 3 de marzo de 2006, F. Jco 6. ${ }^{\circ}$ y STSJAnd

\footnotetext{
28 Dictada contra Acuerdo de la Comisión de Gobierno del Ayuntamiento de Marbella de 13 de marzo de 1998, con pendencia procesal de 5 años y 11 meses.

29 Dictada contra Acuerdo de la Comisión de Gobierno del Ayuntamiento de Marbella de 18 de septiembre de 1998 , con pendencia procesal de 8 años y 10 meses.
} 
11 de mayo de 2006, F. Jco. 5. ${ }^{\circ}$ Pte. Mgtda. Dra. Cardenal Gómez, JUR 2006\265960³0 y $\left.2007 \backslash 822^{31}\right)$.

La apelación al Código Penal en el control de las desviaciones del Ayuntamiento de Marbella, desde 1991 a 2006, ha decantado, desde la demorada disolución de la Corporación, la imagen del control judicial, en detrimento del control preventivo que corresponde ejercer a las autoridades administrativas de supervisión y en detrimento de la misma efectividad del control jurisdiccional contencioso administrativo.

\section{La integración de los contenidos de la Ley de Ordenación Urbanística de Andalucía de 2002}

La Ley 7/2007, de Ordenación Urbanística de Andalucía, bajo el epígrafe «Las licencias ú ordenes de ejecución incompatibles con la ordenación urbanística», Sección 5. a, del Capítulo V, «La protección de la legalidad urbanística y el restablecimiento del orden jurídico perturbado, correspondiente al Título VI, «La disciplina urbanística», en su artículo190, regula la «Revisión de licencias urbanísticas y órdenes de ejecución», y en el precedente artículo 189, establece el régimen de la «Suspensión de licencias y órdenes de ejecución».

El artículo 190, bajo el explícito epígrafe «Revisión de licencias urbanísticas y órdenes de ejecución», establece:

«1. Sin perjuicio de lo dispuesto en el artículo anterior, las licencias urbanísticas y las órdenes de ejecución, así como cualquier otro acto administrativo previsto en esta Ley, cuyo contenido constituya o habilite de manera manifiesta alguna de las infracciones urbanísticas graves o muy graves definidas en esta Ley, deberán ser objeto de revisión por el órgano competente, de conformidad con lo establecido en legislación reguladora del Régimen Jurídico de las Administraciones Públicas y del Procedimiento Administrativo Común.

2. Los procedimientos de revisión, a los que se refiere el apartado anterior, o de declaración de lesividad serán independientes a todos los efectos de los de carácter sancionador».

Y el artículo 189, con el explícito epígrafe, «Suspensión de licencias y órdenes de ejecución, determina la obligación de suspender la eficacia de las licencias u órdenes de ejecución objeto de procedimiento de revisión:

\footnotetext{
30 Dictada contra Acuerdo de la Comisión de Gobierno del Ayuntamiento de Marbella de 26 de junio de 1998, con pendencia procesal de 7 años y 9 meses.

31 Dictada contra Acuerdos de la Comisión de Gobierno del Ayuntamiento de Marbella de 12 de noviembre de 1999 y 21 de enero de 2001, con pendencia procesal de 8 años y 4 meses.
} 
«1. El Alcalde, de oficio o a solicitud de cualquier persona, así como a instancia de la Consejería competente en materia de urbanismo en los casos previstos en el artículo 188.1, dispondrá la suspensión de la eficacia de una licencia urbanística u orden de ejecución y, consiguientemente, la paralización inmediata de los actos que estén aún ejecutándose a su amparo, cuando el contenido de dichos actos administrativos constituya o legitime de manera manifiesta alguna de las infracciones urbanísticas graves o muy graves definidas en esta Ley.

2. El Alcalde procederá a dar traslado directo de la resolución de suspensión al órgano jurisdiccional competente, en los términos y a los efectos previstos en la legislación reguladora de la jurisdicción contencioso-administrativa.

3. Las actuaciones a que se refiere este artículo serán independientes a todos los efectos de las de carácter sancionador.

4. La suspensión administrativa de la eficacia de las licencias conllevará la suspensión de la tramitación de las de ocupación o primera utilización, así como de la prestación de los servicios que, con carácter provisional, hayan sido contratados con las empresas suministradoras, a las que deberá darse traslado de dicho acuerdo».

Las infracciones urbanísticas muy graves o graves tienen la precisa concreción del artículo 207.4.b), que tipifica, como infracción muy grave:

«Las actividades de ejecución sin el instrumento de planeamiento preciso para su legitimación».

E implican la aplicación del artículo 207.3, d):

«La ejecución, realización, desarrollo de actos de parcelación, urbanización, construcción o edificación o instalación, o cualquier otro de transformación del uso del suelo, que sean contrarios a la ordenación territorial o urbanística».

Y en la medida en que implicaran vulneración de medidas cautelares de suspensión, incurrirían en la tipificación, como falta muy grave, por el artículo 207.4, d) de la Ley 7/2002, de Ordenación Urbanística de Andalucía:

«La inobservancia de las medidas cautelares de suspensión ordenadas con motivo del ejercicio de la potestad de protección de la legalidad urbanística y de restablecimiento del orden jurídico perturbado».

La Sala de lo Contencioso Administrativo de Málaga es muy precisa al apreciar la funcionalidad de estos preceptos en el control de la legalidad urbanística.

En Sentencia de 30 de junio de 2007, relativa al Acuerdo de la Comisión de Gobierno del Ayuntamiento de Marbella de 19 de febrero de 2003, que autorizaba la construcción de un centro comercial en superficie a la que el Plan General de 1986 no otorgaba este uso, que no fue recurrida en tiempo y forma, y que la Junta de Andalucía considera ilegal por carecer de cobertura en el Plan 
General de Ordenación Urbana, al no haber sido recurrida en los plazos establecidos por la Ley 30/1992, de Régimen Jurídico de las Administraciones Públicas y 29/1998 de Jurisdicción Contencioso Administrativa, inicia procedimiento de revisión y suspensión de oficio. La Sentencia, después de transcribir el contenido del artículo 190, precisa en sus fundamentos jurídicos:

«Como vemos en el precepto se habla de una posible potestad debida para iniciar la revisión de oficio de licencia cuyo contenido constituya o habilite de manera manifiesta bien una infracción grave o bien una infracción muy grave. Realmente en el precepto se habla de la obligación de revisar estas licencias cuando aparezcan las circunstancias de infracción tipificadas como graves o muy graves. Potestad debida que podemos invocarla para resolver la cuestión de fondo, es decir, si la licencia constituye o habilita este tipo infracciones. Pero que no nos sirve para justificar la adopción de la medida cautelar.

Cuestión distinta es el otro precepto de la legislación urbanística invocado ya que en él si se encuentra un elemento legal que debemos tener en cuenta para hacer la ponderación de intereses en conflicto que aconseja, y exige, la ley procesal en sus artículos 129 y $130 »$.

Y en secuencia con la trascripción del artículo 189, precisa:

«En este precepto la legislación autonómica obliga a la autoridad municipal a suspender la eficacia de una licencia u orden ejecución, pues utilizan el imperativo en la conjugación del verbo «disponer». Aquí sí estamos hablando de una potestad debida cuando haya apariencia de contenido ilegal de una licencia u orden ejecución, y ese contenido ilegal se concrete en la comisión de una infracción grave o muy grave según la propia Ley urbanística.

El legislador no utiliza la posibilidad de que la autoridad municipal pueda suspender o no la licencia que presuntamente se considera incursa en infracción grave o muy grave. Se obliga a adoptar la medida cautelar si hay apariencia de esta grave ilegalidad. Por tanto el legislador urbanístico autonómico está ofreciendo al intérprete una herramienta más para la ponderación de intereses en conflicto cuando deba resolverse una petición de suspensión. El mandato está dirigido al intérprete en sede administrativa, pues habla de "el Alcalde". Pero nada impide pues que esta ponderación de intereses en conflicto, que el legislador autonómico resuelve en favor de la suspensión de efectos de la licencia u orden ejecución, sea aplicada por los órganos jurisdiccionales cuando resuelvan las peticiones de medidas cautelares según la legislación procesal.

Es decir, cuando se contrasten los intereses en conflicto, de una parte el interés que subyace en la petición de la medida cautelar de suspensión y de otra el que subyace en el mantenimiento de la ejecutividad de la resolución impugnada, el órgano jurisdiccional no solamente se regirá por las pautas interpretativas contempladas en los artículos 129 y 130 de la Ley jurisdiccional, sino que junto a estos, podrá contemplar la valoración de los intereses en conflicto que hace el legislador urbanístico. Pues, como hemos visto, en materia de suspensión de los efectos de una licencia u orden ejecución, el le- 
gislador específico opta por la suspensión de los efectos cuando de forma aparente se invoca la comisión o habilitación por la licencia de una infracción urbanística grave o muy grave. El legislador urbanístico opta por evitar que se consoliden situaciones amparadas por una licencia presuntamente ilegal» (STSJAnd 30 junio 2006, F. Jco. 3. ${ }^{\circ}$, Mg. Sr. García Bernaldo de Quirós, JUR 2007\78669²2).

La misma Sala, en Sentencia de 15 de septiembre de 2007, relativa al Acuerdo de la Comisión de Gobierno del Ayuntamiento de Marbella de 25 de abril de 2002, por el que se autorizó la construcción de 52 viviendas en contra de las previsiones del Plan urbanístico vigente, que no fue objeto de recurso, y cuya posible ejecución como acto firme, es recurrida por la Junta de Andalucía en revisión, al amparo de los artículos 189 y 190 de la Ley 7/2002, de Ordenación Urbanística de Andalucía. Los fundamentos jurídicos de la Sentencia inciden en la neutralización, por los artículos 189 y 190 de la Ley 7/2002, de los efectos del transcurso de los plazos para formalizar recursos e integra la valoración jurídico formal de las licencias firmes y ejecutorias, a la que ofrece cobertura la normativa de procedimiento administrativo en la competencia autonómica de control de la legalidad urbanística de las licencias municipales:

«En este mismo orden de ideas, y frente a lo argumentado por las apeladas, debe descartarse que el transcurso de los plazos para iniciar esas últimas vías impugnatorias, como medio equivalente a aquellos recursos administrativos, determine la imposibilidad de iniciar o instar esos otros cauces extraordinarios de impugnación, como así lo reconoce expresamente el artículo 218 del Reglamento de Organización, Funcionamiento y Régimen Jurídico de las Corporaciones Locales, aprobado por Real Decreto 2568/1986, de 25 de noviembre, según el cual “..sin perjuicio de las previsiones específicas contenidas en los artículos 65, 67 y 110 de la Ley 7/1985, de 2 de abril, los órganos de las entidades locales podrán revisar sus actos, resoluciones y acuerdos en los términos y con el alcance que se establece en la Legislación del Estado reguladora del procedimiento administrativo común...”.

Es más, así se reconocía también para este particular ámbito material por el artículo 187 del Texto Refundo de la Ley del Suelo de 1976, y lo asume hoy el artículo 190 de la Ley 7/2002, de 17 de diciembre, de Ordenación Urbanística de Andalucía, al establecer la obligación de revisión de las licencias urbanísticas y las órdenes de ejecución, así como cualquier otro acto administrativo previsto en la Ley, cuyo contenido constituya o habilite de manera manifiesta alguna de las infracciones urbanísticas graves o muy graves definidas en esta Ley. Todo ello, además, según lo declarado por el Tribunal Supremo, por ejemplo, en sus Sentencias de 18 de julio de 1996 (apelación 8506/1991) y de 27 de julio de 1992 (apelación 8221/1990).

Es verdad que los procedimientos contemplados en la Ley 7/1985 se sustentan en el reconocimiento de una especial legitimación en favor de aquellas instancias institu-

32 Dictada contra Acuerdo de la Comisión de Gobierno del Ayuntamiento de Marbella de 19 de febrero de 2003, con pendencia procesal de 2 años y 4 meses. 
cionales en razón a la defensa del ámbito competencial que ostentan o en garantía del cumplimiento del marco normativo que les corresponde tutelar [así puede observarse en el artículo 19.1.d) de la Ley Jurisdiccional], lo que podría hacer pensar que cualquier otro cauce impugnatorio que deseara seguirse por el Estado o las Comunidades Autónomas requeriría la concurrencia de cualquier otro tipo de legitimación. Con todo, aun en ese caso la concurrencia de dicho presupuesto resulta evidente en el supuesto examinado, no ya en virtud de la legitimación popular que en este ámbito reconoce el artículo 304 del Texto Refundido de la Ley del Suelo, aprobado por Real Decreto Legislativo 1/1992, de 26 de junio (no afectado por la STC 61/1997 ni por la disposición derogatoria única de la Ley 6/1998, de 13 de abril), sino a la vista del claro interés directo que la Administración autonómica ostenta a la hora de hacer efectivo el resultado del ejercicio de sus atribuciones en relación con la aprobación del planeamiento urbanístico, que trata de obtenerse a través de procesos como el que ahora se trata» (F.Jco. 2. ${ }^{\circ}$ Pte. Mg. Sr. Hinojosa Martínez, JUR 2007\.77446 ${ }^{33}$ ).

\section{La integración de medidas cautelares y la alegación del principio de seguridad jurídica y de autonomía local, y su ponderación con los intereses supralocales representados por la Comunidad Autónoma}

La Sala de lo Contencioso Administrativo de Málaga integra la brillante doctrina del Tribunal Supremo sobre medidas cautelares:

«Desde la perspectiva del peligro en la demora la Sala también encuentra motivos suficientes para mantenerse en la suspensión acordada. En primer lugar porque desde la óptica municipal el conflicto de intereses en juego no origina una grave perturbación, entendida la competencia urbanística local desde la óptica de la potestad de desarrollar el planeamiento conforme al modelo de ciudad elegido. Ese modelo todavía no está acabado, ni aprobado legalmente al momento de expedirse la licencia. Desde la perspectiva del titular de la licencia, los daños ocasionados por la suspensión serán, en su caso, resarcirles por la Comunidad Autónoma, cuya solvencia se presume y por ello no tiene necesidad de prestar caución. Y desde la perspectiva de los posibles terceros adquirentes, caso de que los haya en estos momentos, es preferible la situación de espera en la posesión de la vivienda que la posible demolición de una vivienda ya habitada.

Frente estos razonamientos no puede esgrimirse, como contrapeso, la existencia de violación de la seguridad jurídica que la suspensión de una licencia concedida pueda implicar. La seguridad jurídica, como indicó la Sala en su momento y fue ratificada su opinión por el Tribunal Supremo en Sentencia Tribunal Supremo (Sala de lo Contencioso-Administrativo, Sección 50), de 10 mayo 2001, Recurso de Casación núm. 5822/1999, está del lado de la Administración que esgrime la utilización normal de las normas que

33 Dictada contra Acuerdo de la Comisión de Gobierno del Ayuntamiento de Marbella de 25 de abril de 2002 , con pendencia procesal de 5 años y 5 meses. 
regulan la expedición de la licencias, es decir, el comportamiento de una Administración conforme a los estándares normativos aplicables a caso concreto. La seguridad jurídica aquí es el reverso del principio de confianza legítima consagrado en el artículo 3.1 de la Ley 30/1992 en la redacción dada por la Ley 4/1999. Esa confianza legítima que tienen los ciudadanos en el comportamiento de los poderes públicos es una garantía y reflejo del principio constitucional de seguridad jurídica. En el caso concreto enjuiciado en esta medida cautelar, significa que los ciudadanos confían en que se ha producido un funcionamiento anormal del procedimiento de aprobación del planeamiento y el ulterior procedimiento de expedición de las licencias urbanísticas. Sí falla la premisa principal, existencia de un Plan que de reforma clara habilita la licencia, no puede argumentarse que la seguridad jurídica se resiente si se suspende esta licencia.

En conclusión, como ya dijimos en la resolución que pronunciamos para suspender la declaración de aprobación por silencio positivo del Plan de Marbella que hizo en su momento el Ayuntamiento, y que ha hecho suyo el Tribunal Supremo en los razonamientos de la sentencia de 10 de mayo 2001, «la petición de suspensión implica un test de razonabilidad (...) operación que a veces debe hacerse con base en la apariencia de buen derecho, es decir, observando superficialmente la pretensión de fondo que se ejercita en el proceso. Este test de racionalidad sobre la petición ha dado como resultado que se considera más adecuado a las finalidad y efectos de la sentencia que pueda recaer en este proceso que no se produzcan situaciones de irreversibilidad en los terrenos sobre los que proyecta sus efectos la licencia, porque la presunción de legalidad que la misma tiene ha fallado de forma aparente, que es lo único que podemos decir en estos momentos. En efecto ni la Sala, ni las propias partes en sus alegaciones, han podido encontrar, de forma clara y ostensible a los efectos del enjuiciamiento cautelar, el respaldo de la licencia en normas del Plan que, sin perjuicio del enjuiciamiento pormenorizado que se pudiera haber hecho en sentencia, permitan deducir el ajuste al planeamiento de la licencia cuestionada. Como el Planeamiento es una competencia también de la Comunidad Autónoma el interés de ésta ha exigido el mantenimiento de la medida acordada.»

Aplicando lo anterior a caso de autos tenemos que la licencia no se encuentra amparada por Plan General o norma de desarrollo que habilite la construcción de lo autorizado. Por otra parte, como alega la propia titular de la licencia, las obras no han comenzado. Es decir, suspender los efectos de una licencia que todavía no ha producido modificación de la realidad física de la parcela no ocasiona una grave perturbación al interés particular y, por el contrario, permitir que en cualquier momento se ejecute la licencia puede ocasionar una merma del peticionario de la medida cautelar respecto del desarrollo de su competencia de planeamiento.

Así las cosas debemos revocar la resolución impugnada y conceder la medida cautelar solicitada por la Comunidad Autónoma» (STSJAnd 30 junio 2006, F. Jco. 4. ${ }^{\circ}$, Mg. Sr. García Bernaldo de Quirós, JUR 2007\78669³4).

34 Dictada contra Acuerdo de la Comisión de Gobierno del Ayuntamiento de Marbella de 19 de febrero de 2003, con pendencia procesal de 2 años y 4 meses, cit. 


\section{La posterior Sentencia no es menos elocuente:}

«Finalmente, en cuanto a la ponderación de los intereses en presencia la Sala se ha referido ya en otras ocasiones al enfrentamiento que en esta materia se produce entre las dos Administraciones presentes en el pleito, reflejo del carácter de las atribuciones públicas en relación con el urbanismo, compartidas entre Corporaciones Locales y las Comunidades Autónomas, en cuyo seno, como así se ha manifestado, «...la ejecución de los planes municipales que corresponde a aquellas Corporaciones no puede entenderse aisladamente (..) sino dentro de un sistema orgánico conjunto en el que las Comunidades Autónomas asumen el papel principal en la fijación de directrices y el control de las actuaciones relacionadas con este campo. De ahí que en casos como el que ahora se trata, deba entenderse que el interés local, concretado en la ejecutividad del acuerdo de concesión de la licencia urbanística que se impugna, no deba prevalecer ante el interés de la Comunidad Autónoma, preeminente y de superior rango jerárquico, en que se respete no sólo la legalidad vigente sino en este caso, el modelo de ordenación legalmente configurado en el PGOU por ella aprobado...»(Auto de 2 de abril de 2003; recurso 1937/2002).

Este juicio de ponderación resulta acorde a la tesis sostenida por nuestro Tribunal Supremo en relación con las exigencias de la autonomía local (Sentencias de 13 de junio de 1990, 30 de enero y 25 de abril de 1991, y 18 de mayo de 1992) y los criterios que deben guiar su control autonómico, que puede recaer sobre el plan «en todos sus aspectos», afecte o no a intereses supralocales (como establecía el artículo 114 del Texto Refundido de la Ley del Suelo de 1992), cuando dicha intervención se sustenta en razones de legalidad, como ocurre en este caso, en el que la Administración autonómica basa su impugnación en la inadecuación a Derecho de la licencia cuya revisión se solicita.

Por lo demás, la Sala (por ejemplo en el Auto que acaba de citarse) se ha ocupado de destacar el carácter inferior del interés particular del titular de la licencia en que la ejecución del acto recurrido no se suspenda, que debe también subordinarse al público. Los particulares intereses del titular de la licencia deben ceder ante los del conjunto de la población de la zona, y ello por cuanto que, como para circunstancias análogas ha declarado nuestro Tribunal Supremo (Sentencia de 27 de julio de 2005; casación 1123/2003), “...la hipotética creación de riqueza no puede erigirse en un interés más digno de protección que la legalidad urbanística...”.

En consecuencia, según todo lo dicho la medida solicitada debió se acordada, lo que impone la estimación del recurso, con la declaración de nulidad de la resolución impugnada y la estimación de la solicitud de suspensión del acto cuya revisión se pretende, sin que, de conformidad con lo establecido por el artículo 139.2 LJCA, se estime procedente formular pronunciamiento alguno sobre las costas causadas en ninguno de los grados» (STSJAnd 15 septiembre 2007, Fs.Jcos. $8 .^{\circ}$ y 9. ${ }^{\circ}$ Pte. Mg. Sr. Hinojosa Martínez, JUR 2007\.77446 $6^{35}$ ).

35 Dictada contra Acuerdo de la Comisión de Gobierno del Ayuntamiento de Marbella de 25 de abril de 2002, con pendencia procesal de 5 años y 5 meses, cit. 


\section{La implicación del concepto de Derecho Urbanístico, del interés supralocal y de la ordenación del territorio}

La referida Sentencia de la Sala de lo Contencioso de Málaga de 11 de mayo de 2007 identifica el concepto de Derecho Urbanístico con:

«El conjunto de reglas a través de las cuales la Administración, en nombre de la utilidad pública, y puntualiza que los titulares del derecho de propiedad, en nombre de la defensa de los intereses privados, deben coordinar sus posiciones y sus respectivas acciones con vistas a la ordenación del territorio».

Y concluye con la precisión de la existencia de un conjunto de intereses:

«En el tema urbanístico estarían implicados varios intereses por una parte los generales que ha de tutelar la Administración y, de otra, los particulares de los que, por regla general, son titulares los propietarios».

Con voluntad de acuñar un concepto, identifica el Derecho Urbanístico con:

«Una rama del Derecho Administrativo cuyas normas tienen por objeto el régimen del suelo, la ordenación del territorio, la transformación del medio y la protección de los derechos y deberes de los sujetos afectados».

Concreción conceptual que tiene el complemento de precisar su ámbito normativo:

«Este Derecho no está integrado exclusivamente por las leyes reguladoras del régimen del suelo sino también por los planes urbanísticos aprobados en aplicación de aquéllas, teniendo especial relevancia dentro de sus fuentes las Ordenanzas Locales expresión natural de la capacidad normativa de las Corporaciones Locales...» (STSJAnd 11 mayo 2007, Cont. Admvo, F. Jco. 4, Pte. Mgtda. Sra. Cardenal Gómez, $\left.2007 \backslash 822^{36}\right)$.

En secuencia con la referencia inicial a los planes de urbanismo, la Sala se proyecta desde ellos a la ordenación del territorio, y a la delimitación, por ellos, del interés público, en un ejercicio de competencias públicas compartidas entre municipios y ente autonómico:

«Los Planes de Urbanismo plasman la ordenación del territorio, estimada como la más adecuada a las exigencias del interés público, más la diversidad de intereses presentes en el plano de urbanismo, necesariamente supone la exigencia de una titularidad compartida, en el planeamiento, por los entes municipales y las Comunidades Autónomas».

36 Dictada contra Acuerdo de la Comisión de Gobierno del Ayuntamiento de Marbella de 12 de noviembre de 1999, con pendencia procesal de 7 años y 6 meses. 
Ejercicio de competencias compartidas, que registra la equilibrada dirimente de que las Comunidades Autónomas que, conforme con la doctrina de la Sala las habilita para que:

«Puedan introducir modificaciones en la aprobación definitiva del planeamiento urbanístico propuesto por los Municipios, sin que tales modificaciones puedan invadir los contenidos propios derivados del principio de autonomía municipal, reconocido en los artículos 137 y 140 de la Constitución y en los artículos 1, 4 y 47 de la Ley 7/1985 de 2 de abril de Bases de Régimen Local en relación con los preceptos 2 y 25 de la misma Ley».

En el supuesto de conflicto de intereses entre los entes públicos intervinientes, la dirimente tiene como referencia la primacía de los intereses supralocales:

«Naturalmente, que en el supuesto de real conflicto o divergencia entre los intereses municipales y los supralocales, han de considerarse estos últimos predominantes».

\section{La Sala constata:}

«El control de las Comunidades Autónomas al aprobar definitivamente el planeamiento, se extiende a los aspectos reglados del Plan en toda su extensión, y en cuanto a los aspectos discrecionales, el control no se extiende a las determinaciones del Plan que no incidan en materias de interés comunitario, con la salvedad que sí son viables los controles, en este supuesto, que tengan por finalidad evitar las vulneraciones de las exigencias del principio de interdicción de la arbitrariedad de los poderes públicos, no siendo, por el contrario admisibles las revisiones de pura oportunidad, ya que en este terreno prevalece el modelo físico que dibuja el municipio».

La Sala concluye con una afirmación descriptiva:

«En cuanto a las determinaciones del planeamiento que tienen conexión con algún aspecto de un modelo territorial superior, sí resulta admisible un control de oportunidad en el que prevalece la apreciación comunitaria».

Afirmación que funda en las Sentencias del Tribunal Supremo de 13 de julio de 1990, 25 de abril de 1991, 18 de mayo de 1992, 21 de marzo de 1994, 17 y 25 de octubre de 1995, y que le permite ofrecer una primer síntesis:

«Por tanto, para concluir, la Comunidad Autónoma tiene obviamente interés supralocal en vigilar la expedición de licencias que puedan afectar a su competencia en materia de aprobación del planeamiento como manifestación del control antes expresado».

En interacción de la jurisprudencia autonómica y del Tribunal Supremo, la doctrina de la Sala de Málaga sobre la integración de intereses administrativos y la alternativa autonómica a los posibles conflictos mediante la delimitación de los intereses supralocales como dirimente confiado al ejercicio de las Comunidades Autónomas, tiene cumplida apreciación en la fenomenología que ha concurrido en el Municipio de Marbella como consecuencia del vacío normativo producido por la carencia de Plan General que, por ausencia de un modelo 
de ciudad, contribuye a perfilar la competencia autonómica al amparo del título y en defensa del interés supralocal:

«La Sala entiende que estamos ante una manifestación clara de este interés supralocal que puede resultar dañado irreversiblemente con la ejecutividad de la licencia, pues la Comunidad Autónoma, que todavía no ha aprobado el modelo de ciudad del cual la licencia impugnada es una anticipación, puede encontrarse, caso de ejecutarse completamente la licencia, ante una pérdida de su función de control legítima dentro del proceso de aprobación del Planeamiento General. O dicho de otra forma, la expedición anticipada de licencias y su completa ejecución hace ineficaz, de facto, la potestad autonómica. Y desde esta óptica estamos ante un supuesto claro de irreversibilidad que justifica la suspensión concedida».

La prevalencia inexcusable del interés supralocal, que está demandado por el principio de confianza legítima, no menoscaba, a juicio de la Sala, el principio de seguridad jurídica:

«Frente estos razonamientos no puede esgrimirse, como contrapeso, la existencia de violación de la seguridad jurídica que la suspensión de una licencia concedida pueda implicar. La seguridad jurídica, como indicó la Sala en su momento y fue ratificada su opinión por el Tribunal Supremo en Sentencia Tribunal Supremo (Sala de lo Contencioso-Administrativo, Sección 50), de 10 mayo 2001, Recurso de Casación núm. 5822/1999, está del lado de la Administración que esgrime la utilización normal de las normas que regulan la expedición de la licencias, es decir, el comportamiento de una Administración conforme a los estándares normativos aplicables a caso concreto. La seguridad jurídica aquí es el reverso del principio de confianza legítima consagrado en el artículo 3.1 de la Ley 30/1992 en la redacción dada por la Ley 4/1999. Esa confianza legítima que tienen los ciudadanos en el comportamiento de los poderes públicos es una garantía y reflejo del principio constitucional de seguridad jurídica. En el caso concreto enjuiciado en esta medida cautelar, significa que los ciudadanos confían en que se ha producido un funcionamiento anormal del procedimiento de aprobación del planeamiento y el ulterior procedimiento de expedición de las licencias urbanísticas. Sí falla la premisa principal, existencia de un Plan que de reforma clara habilita la licencia, no puede argumentarse que la seguridad jurídica se resiente si se suspende esta licencia. (F. Jco. 4. ${ }^{\circ}$, Mg. Sr. García Bernaldo de Quirós, JUR 2007\78669, cit.).

\section{REFLEXIÓN FINAL}

La aprobación del Plan de Ordenación del Territorio de Andalucía ${ }^{37}$ y del Plan de Ordenación del Territorio de la Costa del Sol Occidental ${ }^{38}$ singularizan

37 Decreto 206/2006, de 28 de noviembre, BOJA 29 de diciembre de 2006.

38 Decreto 142/2006, de 18 de julio, BOJA 9 de octubre de 2006. la fecha de aprobación posterior del Plan de ordenación del Territorio de Andalucía está motivada por la intervención parlamentaria en su aprobación y la incorporación de los contenidos de la Resolución del Parlamento de Andalucía. 
los intereses supralocales en el ámbito de la ordenación del territorio y se supraordenan, en un coherente esquema de jerarquía de fuentes normativas, al Plan General de Ordenación Urbanística. Estas aportaciones autonómicas requieren incorporar, al sistema institucional del Estado, la ya inaplazable adecuación de medios a fines en los Juzgados y Salas de lo Contencioso Administrativo, metodología que requiere integrar la actuación procesal informatizada de la Oficina Judicial, con el ya ineludible objetivo de aportar efectividad, en tiempo y forma, a la autorizada doctrina jurisdiccional, de la que son elocuente muestra las Sentencias que anteceden, todo ello como requerimiento exigido por el artículo 24 de la Constitución para materializar los contenidos del derecho a obtener la tutela efectiva de Jueces y Tribunales, objeto de una ya inasimilable demora en el efectivo cumplimiento de unas irrenunciables premisas constitucionales que provocan un severo menoscabo a los efectivos contenidos de nuestro insatisfactorio Estado de Derecho. 



\section{Crónicas y Documentos}


